\title{
Raised blood urea in the elderly: a clinical and pathological study
}

\author{
Lesley K. Bowker ${ }^{1}$, R.S.J. Briggs ${ }^{1}$, P.J. Gallagher ${ }^{2}$ and Dorothy R.C. Robertson ${ }^{1}$
}

Departments of ${ }^{1}$ Geriatric Medicine and ${ }^{2}$ Pathology, Southampton University Hospitals, Southampton SO9 $4 X Y, U K$

\begin{abstract}
Summary: We have attempted to define a normal range for blood urea and creatinine for elderly inpatients and to determine the relative importance of pre-renal, renal and post-renal pathology in those with renal impairment. A total of 118 admissions to an acute geriatric unit and 67 separate post mortems in patients over 67 years of age were studied prospectively. Up to 123 items of data were coded and analysed including blood urea and creatinine, clinical or pathological changes associated with renal disease, clinical outcome and post mortem findings. We determined our own 'normal' hospital ranges for urea (1.4-13.2 mmol/l) and creatinine (48-141 $\mu \mathrm{mol} / \mathrm{l})$ from plasma values in 76 patients with no evidence of renal impairment, either on admission or in the past. Using these values $41 \%$ of post mortem cases and $\mathbf{2 5 \%}$ of clinical admissions had a raised blood urea. Pre-renal conditions such as cardiac failure, dehydration and gastrointestinal haemorrhage, either alone or in combination, were present in $56 \%$ of these patients. Urea and creatinine values were substantially higher in patients who died in hospital as opposed to those who were discharged or transferred. Creatinine values were greater in those with intrinsic renal disease or post-renal obstruction as compared to patients with pre-renal causes of renal impairment. Patients with histological evidence of extensive glomerulosclerosis or nephrosclerosis had higher urea and creatinine levels than those with only minor ageing changes.
\end{abstract}

\section{Introduction}

Many patients have urea or creatinine levels which are well above the normal adult reference ranges but only some have signs or symptoms of renal failure ${ }^{1,2}$ Factors that compromise renal function in the elderly include a progressive age-related fall in both renal blood flow and glomerular filtration rate and structural changes such as sclerosis of glomeruli, renal arteriosclerosis and interstitial inflammation or fibrosis. ${ }^{3-6}$ In addition there is an increasing incidence of conditions which predispose to pre- or post-renal failure, including cardiac failure, dehydration, gastrointestinal haemorrhage and obstructive uropathy. ${ }^{7}$

In this prospective study we have attempted to define a 'normal' range for urea and creatinine in elderly patients and to determine the relative importance of pre-renal, renal and post-renal pathology in this age group. We also examined the value of urea and creatinine estimations in distinguishing between the different causes of uraemia and in predicting mortality.

Correspondence: P.J. Gallagher, M.D., Ph.D., F.R.C.Path., Department of Pathology, Level E, South Block, Southampton General Hospital, Tremona Road, Southampton SO9 4XY, UK

Accepted: 9 October 1991
Methods

\section{Subjects}

All admissions to two acute geriatric wards at Southampton General Hospital were studied prospectively over a 4 month period. The patients were followed until they were discharged or had died. Occasional cases were transferred, discharged or died before urea and creatinine values were available and these were excluded. All post mortems carried out on hospital patients over the age of 65 during a 5 month period were assessed. They were eligible for inclusion if they had at least one urea and creatinine value recorded during their terminal admission. Deaths in the community were excluded.

\section{Data collection and analysis}

In every case, 76 items of data were obtained from the clinical notes, directly from the patient or from the house staff. A further $\mathbf{4 7}$ additional items were obtained at the time of the autopsy (Table I). Renal histological changes were scored from 0 to 18 . Glomerulosclerosis was graded from 0 to $9(<10 \%$ of glomeruli sclerosed to $>90 \%$ ) and arteriosclerosis, interstitial fibrosis and chronic inflammation 
Table I Representative examples of information recorded from clinical and post mortem patients and methods of coding

\begin{tabular}{lll}
\hline Information & $\begin{array}{l}\text { Form of information } \\
\text { or method of recording }\end{array}$ & $\begin{array}{l}\text { Method of } \\
\text { coding }\end{array}$ \\
\hline
\end{tabular}

Age and sex

Weight

Type of admission

Cause of admission

Past medical history

Drugs or medications on admission

Clinical signs

Urea and creatinine

Clinical conditions related to uraemia

Routine investigations

Blood or fluid loss

Recent surgery

Autopsy findings
On admission, or most recent weight

Emergency or routine

Active problem(s) on admission

Previous illnesses noted and in particular evidence of cardiac or renal disease

Noted along with any changes to therapy during hospital stay

16 separate clinical signs recorded on admission plus any changes during individual illness. Included blood pressure, jugular venous pressure, cardiomegaly, pulmonary oedema, evidence of dehydration, gastrointestinal bleeding, etc

All urea and creatinine measurements were noted on the appropriate day

All conditions accepted as potential causes of uraemia were noted (Table III)

Chest X-ray, ECG, haemoglobin and urine microscopy

Any cause of dehydration, especially diarrhoea or vomiting

Less than 1 week post-operative

47 individual findings recorded at time of post mortem, e.g. organ weights, presence or absence of coronary atherosclerosis, hydronephrosis, bladder trabeculation, etc.
Direct coding

Direct coding for weight

Assigned numerical variable

Grouped and assigned numerical variable

Specific numerical codes for presence or absence of individual conditions

Direct coding for total number of drugs, number of diuretics, non-steroidal antiflammatory drugs and medications contraindicated in renal impairment

A numerical code assigned to each condition

Direct coding of 7 days with corresponding urea and creatinine. If more available 7 representative examples chosen

Each cause assigned a numerical code

Numerical coding for presence or absence of any abnormality in each investigation. Haematuria or proteinuria graded 1-4

Numerical code for presence

Numerical code for presence

Usually numerical code for presence or absence. Occasionally coded score of 0 (absent) to 3 (severe) or direct coding for organ weights or ventricular thicknesses were each assessed on a 4-point scale $(0=$ absent, $1=$ minimal change, $2=$ definite abnormality, $3=$ marked abnormality). Potential causes of renal impairment were coded without reference to the actual urea or creatinine concentrations.

Simple data with a small range of values, such as age, were directly translated into numerical codes. Complex data, such as reason for admission, were first grouped into categories of similar values before coding (Table I). A random $10 \%$ of data sheets were rechecked to assess accuracy and reproducibility of coding. Coded information was then processed onto magnetic tape and transferred to the Southampton University IBM 3090/150 mainframe computer for analysis by SPSS-X (Statistical Package for Social Sciences, Part 10).

\section{Results}

\section{Urea and creatinine estimations}

We studied 118 clinical admissions, 44 males and 74 females, median age 85 years (range 69-98 years) and 67 post mortem cases, 36 males and 31 females, median age 77 years (range 66-98 years). The post 
mortem group included 4 patients from geriatric wards who had been included initially in the clinical part of this study. Natural and log-transformed urea and creatinine distributions for all patients on admission are shown in Figure 1. The distributions were markedly skewed to the right (skewness coefficients urea +2.5 , creatinine +3.1 ) but when $\log$ transformed approached a normal distribution.

In order to define normal reference ranges, all cases with no condition associated with renal impairment were identified. The distribution of urea and creatinine in these 76 patients ( 56 clinical cases, 20 post mortem) appeared bimodal but was not obviously skewed (Figure 2). Using all cases in this group the median urea value on admission was $7.0 \mathrm{mmol} / \mathrm{l}$ (range 2.3-14.8) and the creatinine $9 \mu \mathrm{mol} / 1$ (range $41-166$ ). From the mean \pm 2 standard deviations our reference ranges for urea
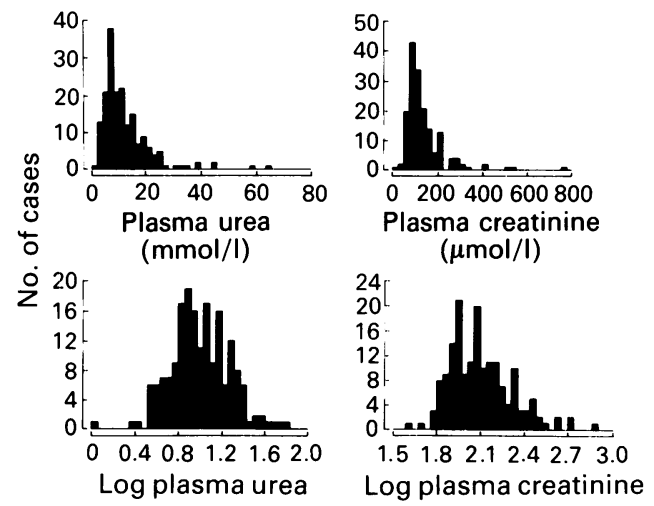

Figure 1 Distribution of blood urea and creatinine on admission in 118 clinical and 67 post mortem cases.

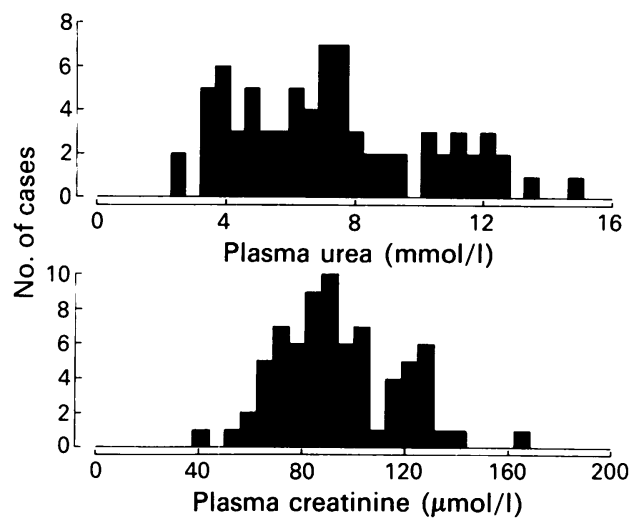

Figure 2 Distribution of blood urea and creatinine in 56 clinical and 20 post mortem patients with no clinical or pathological condition predisposing to renal failure. were $1.4-13.2 \mathrm{mmol} / \mathrm{l}$ and creatinine $47.6-140.6$ $\mu \mathrm{mol} / \mathrm{l}$. When only the 56 clinical cases were considered, ranges were similar (urea 1.0-13.1 $\mathrm{mmol} / \mathrm{l}$ and creatinine $16.7-158.9 \mu \mathrm{mol} / \mathrm{l}$ ).

When all 185 cases, or the 76 'normals', were analysed there was no significant correlation between age and urea or creatinine, or their logged values (data available on request). Plasma creatinine was positively correlated with weight (Spearman's rank coefficient $+0.29, P=0.048)$. As shown in Table II, females were significantly older, lighter and had higher urea:creatinine ratios and in most instances lower plasma creatinines than men. The intersex difference in plasma creatinine was significant when all 185 cases were considered but was not apparent when only the 76 cases with no evidence of renal impairment were selected. There was a close correlation between urea and creatinine for all cases on admission (Spearman's rank correlation coefficient $0.7, P<0.001$ ). The median urea:creatinine ratio was 76 whereas the normal range is usually quoted as $20: 1-30: 1 .^{8}$ There were 107 cases with sufficient data to calculate creatinine clearance by the formula of Cockcroft and Gault. ${ }^{9}$ The mean for all cases was $43.9 \mathrm{ml} / \mathrm{min}$ (s.d. \pm 15.4 ) and median $40.0 \mathrm{ml} / \mathrm{min}$. The mean and median values for 48 of the cases in the group of 76 patients with no overt evidence of renab disease were 45.3 (s.d. 2.1 ) and $41.8 \mathrm{ml} / \mathrm{min}$ respecs tively.

\section{Causes of uraemia}

Any clinical condition conventionally associated with renal impairment was coded for each patient as a 'potential cause', regardless of the actual urea or creatinine value, the clinical condition of the patient or the post mortem findings (Table III) Using the reference ranges calculated above, 63 of the 185 cases $(34 \%)$ had a raised blood urea on admission (30 of 118 acute admissions and 33 of 67 post mortem cases). Thirty-five of 77 patients $(45 \%)$ with one whereas 25 of $32(78 \%)$ with more than one potential cause of renal impairment had urea values $>13.2 \mathrm{mmol} / 1$ (Chi square 4.4 , $P=0.03$ ).

Within the uraemic group, pre-renal causes were most frequent. Cardiac failure, dehydration and gastrointestinal bleeding, either alone or in combination, were present in $56.3 \%$ of all patients with renal impairment. However only $50 \%$ of patients with one or more potential pre-renal cause of uraemia actually had urea concentrations $>13.2 \mathrm{mmol} / \mathrm{l}$. In contrast almost $80 \%$ of cases with post-renal obstruction or evidence of intrinsic renal pathology had raised ureas. In addition creatinine was significantly higher in patients with both renal and post-renal problems when compared with the pre-renal group. 
Table II Clinical and biochemical features of patients studied

\begin{tabular}{|c|c|c|c|}
\hline & $\begin{array}{c}\text { Males } \\
(\mathrm{n}=80)\end{array}$ & $\begin{array}{c}\text { Females } \\
(\mathrm{n}=105)\end{array}$ & $\mathbf{P}^{*}$ \\
\hline \multicolumn{4}{|l|}{ Age (years) } \\
\hline Mean (s.d.) & $80.1 \quad(7.1)$ & $84.1 \quad(6.9)$ & $<0.001$ \\
\hline Median & 80.5 & 85.0 & \\
\hline Type of admission & & & N.S. \\
\hline Emergency & 65 & 90 & \\
\hline Routine & 15 & 15 & \\
\hline Outcome & & & N.S. \\
\hline Died & 42 & 65 & \\
\hline Discharged or transferred & 38 & 40 & \\
\hline \multicolumn{4}{|l|}{ Weight $(\mathrm{kg})$} \\
\hline Mean (s.d.) & $66.0 \quad(14.4)$ & $53.8(13.5)$ & $<0.001$ \\
\hline \multicolumn{4}{|l|}{ Plasma urea $(\mathrm{mmol} / \mathrm{l})$} \\
\hline Mean (s.d.) & $12.0 \quad(8.2)$ & $12.9(10.2)$ & N.S. \\
\hline Median & 9.6 & 9.8 & \\
\hline Plasma creatinine $(\mu \mathrm{mol} / \mathrm{l})$ & & & 0.03 \\
\hline Mean (s.d.) & $160.5(111.5)$ & $134.1(79.2)$ & \\
\hline Median & 133.0 & $111 / 0$ & \\
\hline Urea:creatinine ratio & & & $<0.01$ \\
\hline Mean (s.d.) & 77 (29) & $94(41)$ & \\
\hline Median & 74 & 86 & \\
\hline
\end{tabular}

*Mann-Whitney (age, urea, creatinine and urea:creatinine ratio) or Chi-square test (admission and outcome). N.S. $=$ not significant.

Table III Urea and creatinine values in different patient groups

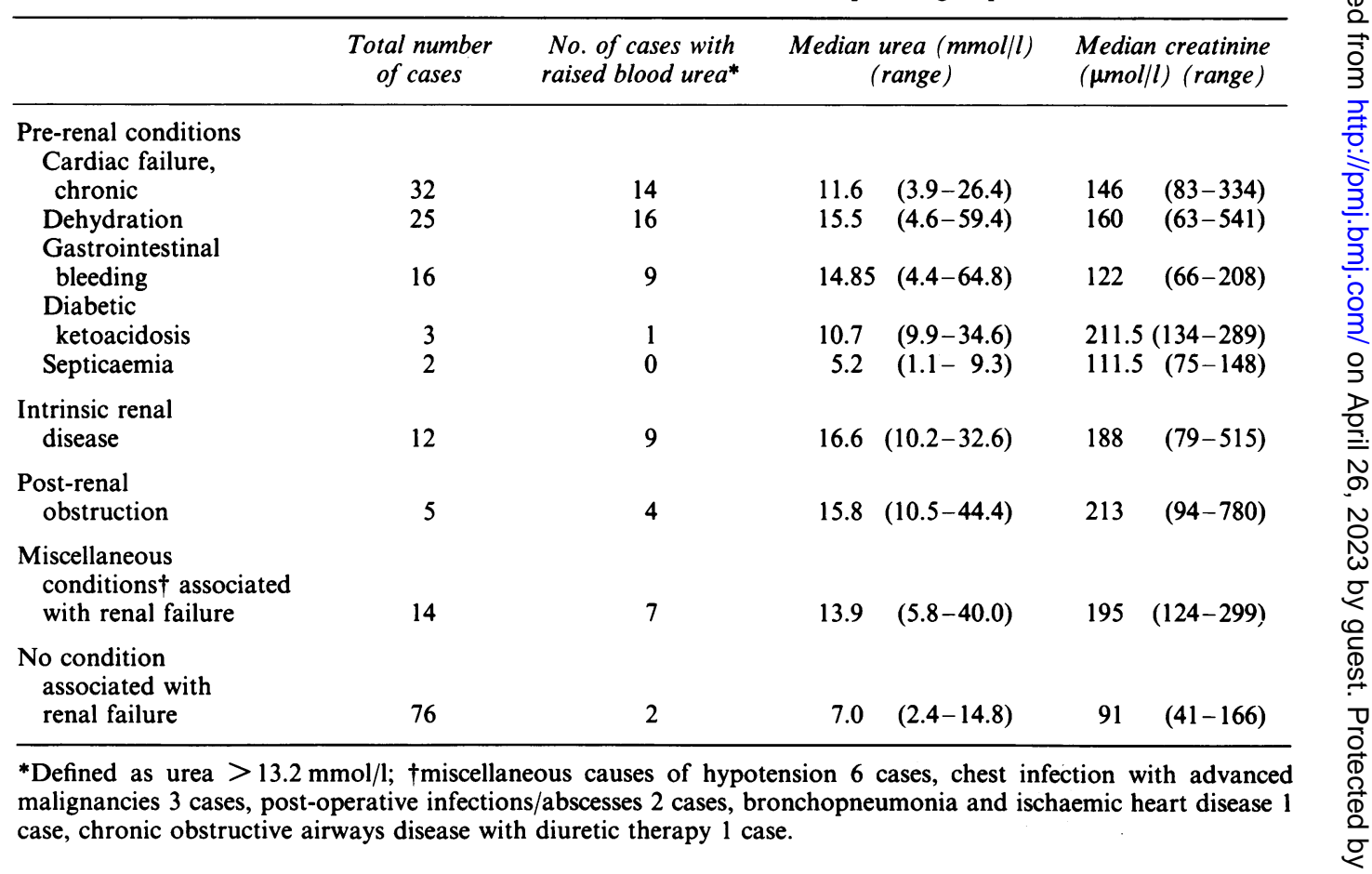




\section{Mortality}

Seventeen of the 118 clinical admissions died in hospital and these had substantially higher urea and creatinine values on admission than the patients who were discharged or transferred (Table IV).

\section{Histology}

Sixty-four of the 67 cases were suitable for histological examination. Forty-five showed varying degrees of ageing change such as arteriosclerosis, glomerulosclerosis, chronic interstitial inflammation or fibrosis. Their composite histological scores (maximum 18) were 6 or less and the percentage of sclerotic glomeruli less than $30 \%$. In these patients there was no correlation between overall histological score and urea or creatinine. However, in the remaining 19 patients, whose histological scores ranged between 7 and 14, the score was correlated with both urea (Pearson's coefficient 0.48, $P=0.01$ ) and creatinine (Pearson's coefficient $0.63, P=0.003$ ). These patients had somewhat higher mean urea $(16.3 \pm 2.1$ s.e.m. $v s$ $13.0 \pm 1.5 \mathrm{mmol} / \mathrm{l})$ and creatinine $(214 \pm 30.0 \mathrm{vs}$ $146.6 \pm 13.2 \mu \mathrm{mol} / \mathrm{l})$ values than those with less marked renal changes. In 12 cases there were major histological abnormalities including recent infarction ( 3 cases), ischaemic atrophy due to chronic renal artery occlusion (3 cases), amyloidosis (2 cases), metastatic tumour deposits ( 2 cases), active tuberculosis and a renal tubular adenoma. In 9 of these cases the renal pathology was a contributory cause of death.

\section{Discussion}

Urea and electrolyte estimation are useful screening investigations ${ }^{10,11}$ but, in the elderly, ure $\mathrm{a}^{12}$ and some other plasma values, such as creatinine, bilirubin, cholesterol and alkaline phosphatase, have a skewed or log normal distribution. It is therefore necessary to define a cut-off point above which patients are considered abnormal and below which they need no further investigation. We calculated our ranges by selecting hospital patients who had no condition that was obviously associated with renal impairment. Of course, as they had been admitted, these patients were not normal and the ranges we obtained for urea $(1.4-13.2 \mathrm{mmol} / \mathrm{l})$ and creatinine $(47.7-140.6 \mu \mathrm{mol} / \mathrm{l})$ were wider than those of fit young subjects. Using these ranges almost $25 \%$ of our 185 patients had 'abnormal' urea values. Our results are broadly similar to other studies in which arbitary limits were set. With an upper value of $12.5 \mathrm{mmol} / 1,20 \%$ of elderly admissions had raised urea levels ${ }^{13}$ but this fell to between 5 and $10 \%$ when $17 \mathrm{mmol} / 1$ was used. ${ }^{7}$

We had the facility to code up to 5 different causes of renal impairment and found that $17.3 \%$ of all cases, and $41 \%$ of those with urea or creatinine values above our upper limit (13.2 $\mathrm{mmol} / \mathrm{l}$ and $140.6 \mu \mathrm{mol} / \mathrm{l}$ ), had more than one potential cause. In contrast 2 previous clinical studies ${ }^{13,14}$ found multiple causes of renal impairment in only 2 and $9 \%$ of patients. However, in 122 patients over the age of 70 admitted to a renal unie in acute failure, the total number of potentia 5 causes of uraemia was almost 230. Like others whot have studied elderly patients, ${ }^{7,13,15}$ we found that pre-renal conditions, especially cardiac failure dehydration and gastrointestinal haemorrhage were the commonest precipitating causes of a raised urea or creatinine.

Post mortem patients were younger and from different sources, including surgical and intensive care wards, than those in the clinical group. In 45 patients the degree of glomerular loss, arteriosclerosis or other change was relatively slight These histological changes were within the spect-

Table IV Plasma urea and creatinine values in relationship to clinical outcome

\begin{tabular}{|c|c|c|c|}
\hline & $\begin{array}{l}\text { Ger } \\
\text { Discharged or } \\
\text { transferred }\end{array}$ & Died & $\begin{array}{l}\text { Post mortem } \\
\text { cases }\end{array}$ \\
\hline $\begin{array}{l}\text { No. of patients } \\
\text { (males:females) }\end{array}$ & $\begin{array}{c}97 \\
(37: 60)\end{array}$ & $\begin{array}{l}17 \\
(7: 10)\end{array}$ & $\begin{array}{c}67 \\
(36: 31)\end{array}$ \\
\hline $\begin{array}{l}\text { Median age (years) } \\
\text { (range) }\end{array}$ & $\begin{array}{c}85 \\
(69-98)\end{array}$ & $\begin{array}{c}85 \\
(72-96)\end{array}$ & $\begin{array}{c}77 \\
(66-98)\end{array}$ \\
\hline $\begin{array}{l}\text { Median plasma urea }(\mathrm{mmol} / \mathrm{l}) \\
\text { (range) }\end{array}$ & $\begin{array}{c}7.7^{\mathrm{a}} \\
(1.1-59.4)\end{array}$ & $\begin{array}{c}14.9^{b} \\
(5.8-44.4)\end{array}$ & $\begin{array}{c}10.9^{c} \\
(2.3-64.8)\end{array}$ \\
\hline $\begin{array}{l}\text { Median plasma creatinine } \\
(\mu \mathrm{mol} / \mathrm{l}) \\
(\mathrm{range})\end{array}$ & $\begin{array}{c}104^{d} \\
(41-360)\end{array}$ & $\begin{array}{c}167^{e} \\
(51-780)\end{array}$ & $\begin{array}{c}144^{\mathrm{f}} \\
(62-541)\end{array}$ \\
\hline
\end{tabular}

*Excludes 4 cases lost to follow-up. Significance of differences using Mann-Whitney tests: a $v s$ b, $P=0.004$; a $v s$ c, N.S.; d vs e, $P=0.009 ; \mathrm{d} v s$ f, N.S 
rum of normal ageing ${ }^{3}$ and were not obviously related to urea or creatinine levels. In the study as a whole only 12 of 185 patients had clinical evidence of intrinsic renal disease. The low incidence of post-renal obstruction in this study is probably the result of our hospital admission policy. Irrespective of age, patients in urinary obstruction are admitted to a urological ward, where on average 8-9 acute cases are assessed each week. ${ }^{16-18}$ As in other studies, we demonstrated that creatinine values were higher and urea:creatinine ratios lower in men than in women. Men were also significantly heavier and, as weight is usually correlated with plasma creatinine, the most likely explanation is that this difference is the result of greater muscle bulk. There was no sex difference in urea, making it unlikely that women had better renal function than men. It is well established ${ }^{19}$ that urinary creatinine excretion per $\mathrm{kg}$ body weight is decreased in the elderly but weight and plasma creatinine were correlated in our 76 patients with no evidence of renal impair-

\section{References}

1. Lindeman, R.D., Tobin, J. \& Shock, N.W. Longitudinal studies on the rate of decline in renal function with age. $\mathrm{J} \mathrm{Am}$ Geriatr Soc 1985, 33: 278-285.

2. Rowe, J.W., Andres, R., Robin, J.D., Norres, A.H. \& Shock, N.W. The effect of age on creatinine clearance in men: a cross-sectional and longitudinal study. J Gerontol 1976, 31: 155-163.

3. McLachlan, M.S.F. The ageing kidney. Lancet 1978, 2: $143-146$.

4. Anderson, S. \& Brenner, B.M. Effects of aging on the renal glomerulus. Am J Med 1986, 80: 435-442.

5. Friedman, S.A., Raizner, A.E., Rosen, H., Solomon, N.A. \& Wilfredo, S.Y. Functional defects in the ageing kidney. Ann Intern Med 1972, 76: 41-45.

6. Larsson, M., Jagenburg, R. \& Landahl, S. Renal function in an elderly population. A study of S-creatinine, ${ }^{51} \mathrm{Cr}$-EDTA clearance, endogenous creatinine clearance and maximal tubular water reabsorption. Scand J Clin Lab Invest 1986, 46: 593-598.

7. McInnes, E.G., Levy, D.W., Chaudhuri, M.D. \& Bhan, G.L Renal failure in the elderly. $Q J$ Med 1987, 64: 583-588.

8. Henry, J.B. Clinical Diagnosis and Management by Laboratory Methods, 17th ed. W.B. Saunders, Philadelphia, 1984.

9. Cockcroft, D.W. \& Gault, M.H. Prediction of creatinine clearance from serum creatinine. Nephron 1976, 16: 31-41.

10. Sewell, J.M.A., Spooner, L.L.R., Dixon, A.K. \& Rubenstein, D. Screening investigations in the elderly. Age Ageing 1981, 10: $165-168$. ment. This was not the case when all subjects were considered, supporting the view that the relationship of creatinine with body weight can be overshadowed by the effects of renal impairment. ${ }^{20}$

We conclude that in geriatric patients blood urea values $>13.2 \mathrm{mmol} / \mathrm{l}$ and creatinine $>141 \mu \mathrm{mol} / \mathrm{l}$ suggest renal impairment. Pre-renal disorders such as cardiac failure, dehydration or gastrointestinal haemorrhage are the leading cause of raised blood urea in the elderly.

\section{Acknowledgements}

We thank Dr H. Eastwood, Dr I. Gove, Dr I. Reid, Dr G.F. Turner and Dr A. Thomas for allowing us to study patients under their care and the pathologists of Southampton University General Hospital for access to their autopsy material. We are particularly grateful to Mark Mullee and Ruth Pickering for their help with data processing and statistical analysis and Julia Berry for secretarial help.

11. Hodkinson, H.M. Value of admission profile testing for prognosis in elderly patients. J Am Geriatr Soc 1981, 29: 206-210.

12. Waters, W.E., Greene, W.J.W. \& Keyser, J.W. Plasma urea concentrations in the general population: comparison with hospital normal values. Postgrad Med J 1967, 43: 695-700.

13. Kafetz, K. \& Hodkinson, H.M. Uraemia in the elderly. J Clin Exp Gerontol 1982, 4: 63-70.

14. Morgan, D.B., Carver, M.E. \& Payne, R.B. Plasma creatinine and urea: creatinine ratio in patients with raised plasma urea. Br Med J 1977, 2: 929-932.

15. Kumar, R., Hill, C.M. \& McGeown, M.G. Acute renal failure in the elderly. Lancet 1973, i: 90-91.

16. Leask, R.G.S., Andrews, G.R. \& Caird, F.I. Normal values for sixteen blood constituents in the elderly. Age Ageing 1973, 2: $14-23$.

17. Briggs, R.S.J. Biochemical screening of normal elderly subjects: longitudinal and cross sectional data. J Clin Exp Gerontol 1986, 8: 27-39.

18. Brochner-Mortensen, J., Jensen, S. \& Rodbro, P. Delimitation of plasma creatinine concentration values for assessment of relative renal function in adult patients. Scand J Urol Nephrol 1977, 11: 257-262.

19. Siersbaeck-Nielsen, K., Molholm Hansen, J., Kampmann, J. \& Kristensen, M. Rapid evaluation of creatinine clearance. Lancet 1971, i: 1133-1134.

20. Bahemuka, M., Hodkinson, H.M., Denham, M.J. \& Padmore, G.R.A. Serum creatinine in a geriatric in patient population. Age Ageing 1973, 3: 43-48. 